\title{
Investigating the Economic Impacts of COVID-19 on the Mental Health of Different Demographics
} \author{
and Yuhsien $\mathrm{Wu}^{\#}$ \\ ${ }^{1}$ McLean High School \\ ${ }^{2}$ Thomas Jefferson High School for Science and Technology \\ ${ }^{3}$ Oakton High School \\ ${ }^{4}$ Marriotts Ridge High School \\ ${ }^{5}$ River Hill High School \\ ${ }^{6}$ Glenelg High School \\ 7James Madison High School \\ ${ }^{8}$ Chantilly High School \\ ${ }^{9}$ Fairfax High School \\ ${ }^{10}$ Langley High School \\ \#Advisor
}

Songhan Pang ${ }^{1}$, Melissa $\mathrm{Wu}^{2}$, Emily $\mathrm{Yu}^{3}$, Aditi Kodali ${ }^{2}$, Kevina Wang ${ }^{3}$, Ray Chen ${ }^{4}$, Karen Song ${ }^{2}$, Victoria Wang ${ }^{2}$, Sophia $\mathrm{Li}^{2}$, Andrew Zhong ${ }^{5}$, David Liu ${ }^{6}$, Elaine Zhang ${ }^{7}$, Jonathan $\mathrm{Luu}^{8}$, Kathleen $\mathrm{Yao}^{9}$, Austin Zhang ${ }^{10}$, Hanna Deller ${ }^{7}$, Drishika Bose ${ }^{2}$, Angela Chen ${ }^{2}$

\section{$\underline{\text { ABSTRACT }}$}

With increases in unemployment and individuals experiencing mental health symptoms, the effects of the COVID-19 pandemic have become a prevalent issue in society. The purpose of this paper is to educate communities about the current effects of COVID-19 on the economy as well as mental health. We aim to establish connections between economic hardships and patterns of depression and anxiety across different demographic groups within the U.S. labor force participation pool aged 18 or older. We analyzed existing literature on past recessions, past pandemics, and the current pandemic's impacts. The findings from past literature suggest that the pandemic has caused various economic impacts which in turn affect mental health, particularly anxiety and depression rates. We used data from the U.S. Census Bureau Household Pulse Survey (HPS) to conduct chi-squared tests of independence on employment income loss and symptoms of anxiety and depression over 12 weeks of the pandemic. For each demographic variable (race, income level, gender, and age), we found an association between each category and experienced employment income loss. The tests yielded the same conclusions for the data of the symptoms of anxiety and depression.

\section{Introduction}

When the United States reported its first Coronavirus Disease (COVID-19) case in January of 2020, the duration and severity of its impact were uncertain. In a couple of months, the pandemic grew rapidly, resulting in detrimental impacts across multiple aspects of society. In March of 2020, states began to place border restrictions and shelter-inplace orders. The rapid increase of COVID-19 cases coupled with strict social isolation caused mass unemployment and feelings of loneliness across the nation. 
Given the drastic changes that the COVID-19 pandemic brought to the U.S. economy and the nation's mental wellbeing, we proposed a connection between the severe economic impacts and their effects on the mental health of different racial groups, income levels, age groups, and genders. This paper analyzes the disproportionate impacts of economic hardships, caused by the COVID-19 pandemic, on patterns of depression and anxiety across different demographic groups, as well as the state of the economy and mental health patterns before, during, and after past recessions, epidemics, and pandemics. Studies of economic trends before and during COVID-19, as well as the actions that have been taken to support the U.S. economy, are analyzed. Furthermore, this paper considers the impacts of COVID-19 on mental health for different racial groups, income levels, age groups, and genders.

\section{Economy Review of Literature}

\subsection{Economy background}

\subsubsection{Past recessions: The Great Depression and Great Recession}

The 1920s was a period of rapid economic development and rising stock prices. In 1929, the economy slowed down and entered a recession (Romer, n.d.). Over the ten weeks following October 29, 1929, the value of stocks fell by roughly 50\% (Library of Congress, n.d. -a). As a result of the stock market crash, companies began to engage in massive layoffs, resulting in a peak unemployment rate of 24.9\% (Amadeo, 2020c). African Americans were affected the most heavily, with around half of all African Americans being unemployed by 1932 (Library of Congress, n.d. b).

The Great Recession (2008 Financial Crisis) lasted from December 2007 to June 2009, marking the longest and most severe recession since WWII (Schanzenbach et al., 2016; Rich, 2013). One major cause behind the crisis was the lending of subprime mortgages, which left many debtors unable to pay off these loans. (Duca, 2013; Consumer Financial Protection Bureau, 2017). Hoynes, Miller, and Schaller (2012) explained that unemployment rates during this recession soared to $10 \%$, the U.S. lost 5.5 million jobs, and unemployment affected male, young, and less-educated workers the most (Schanzenbach et al., 2016; Swagel, 2010).

Both the Great Recession and the 2020 recession led to government acts to alleviate financial stresses. Like the Great Recession, young workers in the COVID-19 induced recession have been affected by unemployment at a greater rate.

\subsubsection{Past pandemics: S.A.R.S. and H1N1 swine flu}

The outbreak of Severe Acute Respiratory Syndrome (SARS) resulted in a global recession. The cost of the pandemic was \$30-100 billion of the global economy. As a result of the pandemic, China saw a 1\% decrease in its GDP, and the global economy had a $0.1 \%$ decrease in GDP (Qiu et al., 2018). Although this unprecedented virus led to increased panic buying, the overall demand for goods and services significantly decreased (Qiu et al., 2018). However, the losses from this quarter were almost equivalent to the gains of the following quarter.

The H1N1 swine flu originated in the U.S. and spread globally in 2009 (Chakravarty \& Philipose, 2009). A World Bank study by McKibbin and Sidorenko (2006) found that a severe outbreak of the swine flu resulted in an approximate 5\% decrease in GDP for high-income nations. The primary contributor to the economic fall was the lack of consumer demand. The rapid permeation of the swine flu caused many businesses and even entire industries to be shut down.

The SARS and H1N1 swine flu pandemics caused economic losses, whether it be in the aggregate or only for specific industries. Due to reduced demand, the recessions led to lower prices and greater difficulty for businesses and employers to pay their employees, which then raised unemployment numbers. The COVID-19 pandemic follows this path of economic debilitation as well. Both pandemics had an indiscernible impact in the overall economic trends, showing that the long term economic impacts of pandemics depended heavily on the status of the economy right before the pandemic arrived. 


\subsection{Economic impacts of COVID-19}

\subsubsection{General effects of COVID-19 on the economy}

According to Miller and Labonte (2020), the U.S.'s real GDP fell at a 4.8\% annual rate during the first quarter of 2020. In the second quarter of 2020, GDP fell at a 34.3\% annual rate, two-thirds of which can be attributed to a negative shock in aggregate supply (Bekaert, Engstrom, \& Ermolov, 2020). As COVID-19 continued to spread across the U.S., individuals hesitated to travel outside of their homes due to health concerns, which heavily impacted the service and manufacturing sectors. Shelter-in-place policies have also resulted in countless layoffs, as workers in the manufacturing industry are unable to telework (Nicola et al., 2020). The lockdown measures taken to mitigate the impacts of COVID-19 are causing a global reduction in both production and consumption. Lenzen et al. (2020) found that as of May 2020, the pandemic has triggered a global consumption loss of $\$ 3.8$ trillion, 147 million full-time job losses, and a total income loss of \$2.1 trillion, with consumption losses accounting for 4.2\% of global GDP (Lenzen et al., 2020). Worldwide consumption losses resulted in supply-chain shifts that led to global losses of income, employment, and reductions of emissions (Lenzen et al., 2020).

\subsubsection{Economic impacts by racial groups}

The COVID-19 pandemic has resulted in vast unemployment across the U.S., as indicated by mass layoffs and business closures. After reaching a peak unemployment rate of 14.7\% in April 2020, unemployment fell slightly in the following months but continued to remain significantly higher than pre-pandemic levels (U.S. Bureau of Labor Statistics, 2020). The data collected over the pandemic period demonstrates that the economic effects of COVID-19 brought a greater burden to people of certain races over others. In April, the unemployment rates were $18.9 \%$ for Hispanics and Latinos, 16.7\% for Black people, 14.5\% for Asians, and 14.2\% for Whites (U.S. Bureau of Labor Statistics, 2020). During the following months, Hispanics and Black people continued to suffer higher unemployment compared to Asians and Whites. Wardrip and Tranfaglia (2020) found that the occupations most at risk of job or income cuts during COVID-19 are those that spend a large amount of time working in close proximity to others, excluding health care and essential workers. According to the Federal Reserve Bank of Philadelphia, around 45\% of non-Whites and Latinos belong to the at-risk worker population. In 2018, 23\% of Black people and 19\% of Hispanics were below the federal poverty line, as compared to only $11 \%$ of Whites (Noppert, 2020). As such, non-Whites were disproportionately disadvantaged even before the pandemic. These inequities were exaggerated even further by the economic effects of COVID-19.

There are various factors affecting the health of minority races, the most prominent of which are preexisting health conditions and lack of quality health care. Racial minorities, especially Hispanics and Latinos, African Americans, and Native Americans, have less access to healthcare because they often live in places far from healthcare facilities and are economically disadvantaged. On top of maintaining social distancing, furloughed or unemployed Americans are also experiencing pressures in the home setting. Black households had higher chances of experiencing difficulties making housing and other bill payments $(\mathrm{p}<.001)$ and putting off filing prescriptions $(\mathrm{p}<.05)$ compared to White households (Despard et al., 2020). Hispanic households had a statistically greater chance of experiencing food insecurity ( $\mathrm{p}$ <.001) compared to White households (Despard et al., 2020). Due to pre-existing inequalities in health, income, and employment, Hispanic and Black individuals experienced the greatest economic difficulties compared to other races during the COVID-19 pandemic.

\subsubsection{Economic impacts by income levels}

In comparison to other financial groups, low-income workers are more impacted by the possibility of unemployment during COVID-19 because low wage work typically cannot be done at home. The Pew Research Center conducted a survey in March 2020 which found that $61 \%$ of high-income individuals reported working at home because of COVID19 , whereas only $41 \%$ of middle-income individuals and $27 \%$ of low-income individuals were able to (Pew Research Center, 2020). An AmeriSpeak Panel survey conducted in early April found that over half of low-income workers are 
concerned about being laid off, whereas only $20 \%$ of higher-income workers are concerned about job loss (Bertrand, 2020). Thus, there is a disparity in employment security between higher-income and lower-income individuals. Additionally, many low-income families might not have received the financial support that they needed from the Coronavirus Aid, Relief, and Economic Security (CARES) Act.

As with past patterns of pandemics, lower-income individuals are disadvantaged in receiving healthcare and struggle to follow social distancing orders because of work or transportation needs (Henry-Nickie \& Hudak, 2020). According to Wilson (2020), data from the neighborhoods of New York show that poorer neighborhoods tend to have higher cases of COVID-19 because of poor living conditions and high-risk jobs. In addition, lack of healthcare is a major obstacle for many lower-income families.

Low-income families also struggled with paying their bills during this pandemic. An April 2020 study by Parker, Horowitz, and Brown (2020) surveyed 4,917 U.S. adults and found that only $23 \%$ of low-income families who make less than $\$ 37,500$ annually have saved rainy day funds that can support their families for three months. The study found that $48 \%$ of middle-income $(\$ 37,500$ to $\$ 112,600)$ and $75 \%$ of high income (more than $\$ 112,600$ ) individuals have rainy day funds set aside (Parker, Horowitz \& Brown, 2020).

\subsubsection{Economic impacts by age groups}

The negative effects of the COVID-19 pandemic on the labor market have impacted specific age groups. A Pew Research poll found that among the $28 \%$ of adults that were laid off and the $33 \%$ of adults that received a cut in income, there was a negative relationship between the probability of unemployment/income cut and age; $54 \%$ of those aged 18-29 faced some sort of work disruption, while it was 49\% for ages $30-49,42 \%$ for ages $50-64$, and $25 \%$ for ages 65 and over (Schaeffer \& Raine, 2020). A primary factor contributing to the heavy burden on younger workers under 30 is that they are typically employed in high-risk industries, including service sector positions (Kochhar, 2020a). Older workers also experienced extensive economic damages, as nearly 5 million older workers lost their jobs in the peak of COVID-19 (Kochhar, 2020a). The elderly went through the largest change from pre-pandemic conditions; between April and March 2020, the unemployment rate for older workers increased four-fold from approximately $4 \%$ to $16 \%$ (Cubanski, Neuman \& Koma, 2020). The young entrants of the labor market will have a more difficult time finding employment, given that the main contributor to job qualification—education-has been severely disturbed.

When it comes to daily life, COVID-19 created fear and paranoia surrounding activities that were once seen as common and safe. A Pew Research study found that $40 \%$ of adults aged between 18 and 29 consider COVID-19 to be a major threat to their finances (Schaeffer \& Rainie, 2020). The study also concluded that $43 \%$ of the population between 30 and $49,46 \%$ of the population between 50 and 64, and 32\% of the population 65 and older worry about COVID-19's impact on their finances (Schaeffer \& Rainie, 2020). Based on the data, the younger population faces greater unfavorable financial impacts due to COVID-19.

\subsubsection{Economic impacts by gender}

The COVID-19 pandemic resulted in surging rates of unemployment in many sectors and industries, namely leisure, hospitality, education, retail, and health services. These industries constitute $47 \%$ of women's jobs and only $28 \%$ of men's jobs, and often require extensive physical contact (Kochhar, 2020a). Because women are overrepresented in many of the sectors which are unable to operate through teleworking, they experience more job or income loss than men. To further measure the effects of the pandemic on certain sectors, a study by Kochhar (2020b) found that from February to May of 2020, employment fell by 39\% in the leisure and hospitality sector and $15 \%$ in the education sector. Within the same time frame, more women (11.5 million) experienced job loss than men (9 million) (Kochhar, 2020b). Furthermore, women are more likely to hold marginal, low-authority positions and to have the shortest tenures, so they are more susceptible to being laid off (Kalev, 2020). Globally, women makeup 70\% of the health workforce and are more likely to be front-line health workers (United Nations, 2020). Because women are the majority of health facility service-staff (cleaners, laundry, catering), they are more likely to be exposed to the virus (United 
Nations, 2020). Although the economic impacts of COVID-19 harm parents across the board, single mothers are severely overloaded with balancing familial duties and finances. In April, the number of single mothers with a job was $22 \%$ lower than last year, but only $9 \%$ lower for other parents (Levine, 2020).

\section{Mental Health Review of Literature}

\subsection{Mental health background}

\subsubsection{Impact of past recessions and pandemics on mental health}

Depression and anxiety disorders become prevalent among young adults during economic recessions. Apprehensions of the deflating economy created conditions that increased rates of depression and anxiety, as supported with research administered by Yilmazer, Babiarz, and Liu in 2015 which found that the sharp decline in real estate price values during that time was correlated with individuals experiencing higher levels of stress, depression, and unhealthy lifestyles (Mather, 2015). The Great Recession also induced a significant increase in the use of antidepressant drugs, which correlated with the rise in the number of depression and anxiety cases (Forbes \& Krueger, 2019). In 2013, Leist, Hessel, and Avendano found that both women who experienced a recession during the ages of 25-44 and men who experienced a recession during the ages of 45-49, displayed a decline in cognitive function in later years (Mather, 2015). Based on the outcomes of previous economic recessions, it is evident that Americans are put at a substantially higher risk for lasting mental health effects during recessions.

Severe Acute Respiratory Syndrome (SARS) was the first viral infectious disease to impact the 21st century. A study by Mak et al. (2009) indicated that ten to thirty percent of recovered patients reported feeling symptoms of anxiety, depression, or both while recovering. Additionally, $45 \%$ of the respondents in studies conducted by the Structured Clinical Interview for the Diagnostic and Statistical Manual of Mental Disorders experienced at least one active diagnosable psychiatric disorder within the first two to four weeks after discharge (Mak et al., 2009). Mak et al. (2009) also noticed that after the pandemic, a third of those in the study continued to suffer from psychiatric disorders.

After the Ebola epidemic in 2014, studies performed of the residents in Sierra Leone reported by Jalloh et al. in 2018 found that $48 \%$ of those surveyed had at least one symptom of anxiety or depression. Among the respondents, $47 \%$ reported symptoms of both anxiety-depression and post-traumatic-stress disorder (PTSD). Risk factors that may have caused symptoms to arise include experience in taking care of sick individuals, perception of the initial threat, food and resource insecurity, and intolerance of the uncertainty. Symptoms of depression, anxiety, and PTSD were common even after one year of the initial outbreak of Ebola (Jalloh et al., 2018).

\subsubsection{Past trends in depression and anxiety by racial groups}

Existing studies on depression patterns in the African American, Black Caribbean, non-Hispanic White, and Hispanic populations have yielded different conclusions. For instance, Williams et al. (2007) examined major depressive disorder (MDD) in large samples of African Americans, Black Caribbeans, and non-Hispanic Whites taken from the National Survey of American Life using modified interview diagnostics from the World Health Organization. Their findings concluded that non-Hispanic Whites were more susceptible to lifetime MDD (17.9\%), as compared to Black Caribbeans and African Americans. However, Black Caribbeans and African Americans have higher rates of chronicity (56.5\% and 56.0\%, respectively), as compared to $38.6 \%$ for non-Hispanic Whites (Williams et al., 2007; American Psychiatric Association, 2017). On the other hand, Dunlop et al. (2003) found that reports of major depression in U.S. individuals aged 54-65 were most frequent among African Americans and Hispanics (8.85\% and 10.78\%, respectively) than whites (7.75\%). Existing data has strong implications that minority groups may be more susceptible to depression that is caused by economic disparities.

Asnaani et al. (2010) found that White Americans were more likely than minority groups studied to be diagnosed with social anxiety disorder (SAD), generalized anxiety disorder (GAD), and panic disorder (PD), whereas 
PTSD was more prevalent in African Americans. These elevated rates of PTSD could be due to high exposure to violent or crime-induced environments or increased risk of racism (Himle et al., 2009). In addition, higher rates of GAD, SAD, and PD among non-Hispanic Whites may be due to preexisting mood disorders or substance abuse disorders, the latter being a higher risk to Whites than Black people (Breslau et al., 2005). Therefore, it is likely that the cultural background and the context of home environments account for a portion of past trends in anxiety among these racial groups.

\subsubsection{Past trends in depression and anxiety by income level}

Experiencing economic hardship can often lead to the emergence of mental illness (Mossakowski, 2014). This theory is supported by the higher rates of depression among people with mild to severe financial strain (Dijkstra-Kersten, 2015). This may be the result of repeated exposure to stressors such as high crime rates, which increase cortisol levels and lead to lasting disruptions in brain patterns and functioning (ADAA, 2020). Inability to access care may also cause stressors and increase the risk of experiencing depression and anxiety (Bartsuka, Shtasel, \& Marques, 2020).

Other studies have shown, however, that financial strain is not associated with recurring depression or anxiety disorders (Dijksra-Kersten et al., 2015). This prompts the question of whether income-related mental health issues are caused by financial strain itself or disparities between incomes in certain areas, as living in areas with higher levels of income inequality is associated with a greater risk of depression. (Chiavegatto Filho et al., 2013).

\subsubsection{Past trends in depression and anxiety by age group}

According to survey data from the Substance Abuse and Mental Health Services Administration (SAMHSA), the percentage of adults affected by any mental illness (AMI) decreased with increasing age, with $25.8 \%$ of adults aged 18 to $24,22.2 \%$ of those aged 26 to 49 , and $13.8 \%$ of adults who are 50 and older having a diagnosed mental illness in 2017 (National Institute of Mental Health, 2019b).

The percentage of adults diagnosed with MDD also decreased with age in 2017 , with $13.1 \%$ of U.S. adults aged 18-24 showing symptoms of this disorder, compared to 7.7\% of adults aged 26 to 49 and $4.7 \%$ of adults aged 50 and older in 2017 (National Institute of Mental Health, 2019a). While this trend was consistent between MDD and mental disorders overall, anxiety disorders were actually more prevalent among middle-aged adults. As reported by the National Institute of Mental Health (2017), in 2017, of U.S. adults aged 33 to 44 and 45 to 59, the percentage of those diagnosed with an anxiety disorder were $3.5 \%$ and 3.4\%, respectively, the highest percentages of the age groups. Like depression, however, the oldest age group had the lowest percentage of anxiety disorders, with $1.5 \%$ of U.S. adults aged 60+ affected by one (National Institute of Mental Health, 2017).

\subsubsection{Past trends in depression and anxiety by gender}

Due to many pre-existing factors such as having a tendency to lead family health, women are more likely to be diagnosed with major depressive disorder; while 1 in 10 men have major depressive disorder, 1 in 4 women have major depressive disorder (RAMH, n.d.). Although these statistics are from U.K. adults, they are comparable to those of U.S. adults. Hormones play a significant role in men and women's vulnerability to depression. Prevalence of depression is associated with the constant fluctuation of hormones in women during puberty, before menstrual cycles, following pregnancy, and during menopause (Albert, 2015). Studies on rodents show that estrogen, a female hormone, has an impact on depression. Because men produce estrogen through a different cycle, estrogen does not negatively affect the mental health of men. Additionally, the main male hormone, testosterone, is shown to decrease the risk of depression and anxiety (McHenry et al., 2014). Another factor which influences mental health are gender roles. In industrialized countries, frequent exposures of illness or death of children in their household, job insecurity, and dangerous neighborhoods and workplaces causes women to be at a higher risk of developing depression than men (Department of Gender and Women's Health, 2002).

Women are two times more likely to have an anxiety disorder than men, and $60 \%$ of U.K. adults with a phobia or obsessive compulsive disorder (OCD) are women (RAMH, n.d.). Data from the Collaborative Psychiatric 
Epidemiology (CPES) studies show that women have a higher diagnosis rate for lifetime anxiety disorders, with rates of $33.3 \%$ for women compared to $22 \%$ for men (Mclean et al., 2011). Women are also more likely to develop post traumatic stress disorder (PTSD) than men, with rates of $20.4 \%$ and $8.4 \%$, respectively (RAMH, n.d.). This is due in part to their increased exposure to domestic violence (RAMH, n.d.).

There are many differences in mental disorders between different ages and gender. Adolescent girls are more likely to experience depression and eating disorders than adolescent boys (Department of Gender and Women's Health, 2002). Additionally, adult women are more likely to be diagnosed with depression or anxiety, while men are more likely to experience substance abuse disorders and antisocial behaviors (Department of Gender and Women's Health, 2002). Suicide rates are higher among men than women, but there are more suicide attempts by women (Department of Gender and Women's Health, 2002). A possible explanation for this is the tendency for women to be more expressive with their emotions and seek help if necessary (RAMH, n.d.). Women with children are also less likely to die by suicide due to their role as a mother (RAMH, n.d.).

Other social factors that may increase the prevalence of mental health conditions among women include the fact that more women live in poverty than men and have a greater responsibility caring for the family (RAMH, n.d.). Women are more likely to experience psychological disorders due to reproductive health conditions and problems. For example, infertility increases a women's risk of affective/neurotic syndromes (Department of Gender and Women's Health, 2002). While anxiety and depression heavily impact both genders, women are overall more likely to develop these mental health conditions.

\subsection{Trends in depression and anxiety due to COVID-19}

\subsubsection{Overall trends}

Prior to the COVID-19 pandemic, $19.1 \%$ of all U.S. adults experienced any mental illness (AMI), and serious mental illness (SMI) affected 4.6\% of the same population (National Alliance on Mental Illness, 2019). According to a poll conducted by the Kaiser Family Foundation, almost half of Americans surveyed reported that the COVID-19 pandemic had negatively impacted their mental health (Wan, 2020). Data from helplines and other virtual mental health resources echo this increase in mental health cases. Talkspace, a company that provides online therapy, reported that the number of users increased by $65 \%$, many of whom stated that the coronavirus was the cause of their stress (Wan, 2020).

Prolonged social isolation, uncertainty, economic burdens, and further stressors brought by the COVID-19 pandemic have caused concerning increases in the prevalence of anxiety disorders. By early July of 2020, 34\% of the U.S. adult population surveyed reported symptoms of anxiety disorder, a 3.2\% overall increase from April 2020. In contrast, from January to July of $2019,8.2 \%$ of U.S. adults surveyed had symptoms of anxiety disorder, indicating a considerable 25.8\% increase from 2019 to 2020 (Centers for Disease Control and Prevention, 2020).

Following anxiety disorders, major depressive disorder (MDD) was the second most common mental health condition in 2018, affecting 7.2\% of U.S. adults (National Alliance on Mental Illness, 2019). A major effect of mental illness is suicide, which is the second leading cause of death of Americans aged 10-34 (National Alliance on Mental Illness, 2019). Of the individuals who died by suicide, $46 \%$ had a diagnosed mental disorder and $90 \%$ showed symptoms of one (National Alliance on Mental Illness, 2019). Overall, the rates of depressive disorder symptoms in the U.S. adult population increased each week, except for one week of the ten studied according to data from the Centers for Disease Control and Prevention (2020).

\subsubsection{Trends by racial groups}

Among the large percentage of Americans who show increased symptoms of anxiety and depression, minority groups are reported to be disproportionately affected (SAMHSA, n.d.). The shocks brought by the pandemic revealed distinct vulnerabilities in the American healthcare system for certain racial groups (Graham et al., 2020). The presence of 
multiple stressors such as the economic recession and high rates of mortality are often found to be especially impactful among minorities in comparison to Whites and may be the reason behind these disparities (Bartuska et al., 2020). There is an observable spike in symptoms of depression among certain racial groups as a result of the COVID-19 pandemic; In the United Census Bureau Household Pulse Survey, large numbers of Hispanic, Latino, and Black people reported frequently feeling little interest or pleasure in doing activities and/or frequently feeling hopeless (United States Census Bureau, 2020a). However, there is still limited data that analyzes the rates of these feelings among different races in the U.S.

\subsubsection{Trends by income levels}

The consequences of the pandemic are often greater for certain income levels. Americans who make less than $\$ 40,000$ annually report levels of worry at rates 10\% higher than their middle-income counterparts (Kirzinger et al., 2020). Additionally, a Pew Research Center American Trends Panel survey conducted in March of 2020 showed that lowincome groups experienced a substantially higher rate of psychological distress of 33\% compared to that of high income groups who only had a rate of $17 \%$ (Purtle, 2020).

A higher percentage of low-income Americans do not have a safety net for paid sick leave or paid family leave (Kirzinger et al., 2020). As a result, low-income groups typically show a higher rate of infection and mortality during pandemics, which could contribute to "elevated levels of grief and psychiatric morbidity" in such groups (Purtle, 2020). Another stressor that leads to mental health consequences is a loss in employment income, which has mainly affected lower-income groups. Half of adults with an income of less than $\$ 25,000$ had "no/slight confidence" in their ability to pay the next month's rent, whereas only $8.4 \%$ of adults with an income of $\$ 100,000$ or more felt that way (United States Census Bureau, 2020a).

\subsubsection{Trends by age groups}

An indirect effect of COVID-19 is that it hinders the growth of a healthy mentality in young adults. The percentage of people who experienced symptoms of anxiety or depression decreased as the age increased. For example, $36.2 \%$ of young adults ages 18 to 29 experienced symptoms of depression, and $41.6 \%$ of the same group experienced symptoms of anxiety from April 23rd to July 7 th. In contrast, $13.7 \%$ of adults aged 80 or older experienced symptoms of depression and $14.3 \%$ experienced symptoms of anxiety (CDC, 2020).

Isolation paired along with their lack of expertise in technology leaves elders with feelings of loneliness (Banerjee, 2020). However, they have been suffering from feelings of loneliness before the arrival of COVID-19, meaning that they are more familiar with isolation and have thereby become more tolerant to its impact on mental health when compared to younger adults (Gramigna et al., 2020). Since those within the ages of 18-50 have not had to deal with constant loneliness prior to COVID-19, the struggle that they face with isolation becomes ever-more prevalent. Moreover, a poll conducted by the Institute of State and Regional Affairs (ISRA) at Penn State University provided data which stated that $69 \%$ of those between the ages of 18 to 24 reported that COVID-19 had a "negative impact" on their mental health. Although older adults experience a direct impact from COVID-19 due to physical health concerns, the worsening mental health of young adults and adults needs to be acknowledged as this effect may prove to be more detrimental in the long-term.

\subsubsection{Trends by gender}

Since the beginning of quarantine, anxiety rates among U.S. adults have been on the rise (Hamel \& Salganicoff, 2020). However, COVID-19 has had differing levels of impact on the mental health of men and women. According to a study by Miyamoto (2020), women comprise $70 \%$ of the healthcare workforce and account for $73 \%$ of infected healthcare workers in the U.S. Data also shows that women in healthcare experience more severe symptoms of depression and anxiety than men in the same field (Miyamoto, 2020). Moreover, the amount of stress that women have experienced throughout quarantine is shown to be greater than that of men. In a recent Kaiser poll, 53\% of female respondents reported that COVID-19 had a "significant negative impact on their mental health" while only $37 \%$ of male 
respondents reported such an impact (Hamel \& Salganicoff, 2020). The disparities between the mental health of men and women could be attributed to how women usually have a greater responsibility to care for others than men. Women with children experience greater feelings of depression and anxiety since they are usually the main caregiver in many households during this crisis. Around $61 \%$ of women find it difficult to stay positive on a day-to-day basis compared to $47 \%$ of men (Lock, 2020).

According to a survey conducted in 2020 by the Centers of Disease and Control Prevention, women had a $5.3 \%$ jump in anxiety symptoms, while males reported a $7.4 \%$ increase. However, it is important to note that the initial rate of anxiety symptoms in females was 35.4\% while the initial rate for males was $26.1 \%$ (CDC, 2020). A trend in anxiety levels within working women and men would corroborate how women experience anxiety symptoms more often than men. In terms of depressive symptoms, females experienced a net increase of $6.3 \%$ compared to an $8.2 \%$ net increase in males (CDC, 2020). Similar to anxiety, it is imperative to keep in mind that the initial rate of depressive symptoms is significantly higher in females than males, with females starting at $25.1 \%$ and males at $20.8 \%$ (CDC, 2020). Comparable to anxiety, data also proves how working women experience higher rates of depression symptoms than working men.

\section{Methods}

The U.S. Census Bureau, along with five federal partner agencies, created the 2020 Household Pulse Survey (HPS) to measure the social and economic effects of the COVID-19 pandemic on American households and guide governmental and non-governmental response accordingly. The survey spanned twelve weeks, from April 23 to July 21 . The U.S. Census Bureau used the Master Address File (MAF) and Census Bureau Contact Frame to select a representative sample of the United States and conducted the survey through email and telephone contact, with 140,000,000 housing units considered across the nation. The survey was administered through the Qualtrics Data Collection Platform, and the data were collected over 90 days and released each week. Although this online method was expected to have a lower yield than traditional in-person or mailing methods, it was chosen due to the efficiency, timeliness, and low cost of responses.

The HPS asked questions regarding employment status, spending patterns, food security, housing, physical and mental health, access to health care, and education disruption. This study focuses on the employment and mental health aspects of the COVID-19 pandemic, and therefore centers analysis around those two areas. The employment questions ask about the respondents' loss of employment, work experience within the past seven days, and reasons for not working. The mental health section consists of four questions, two addressing anxiety and two addressing depression. The questions regarding anxiety measured the frequency of feeling nervous, anxious, or on edge and the frequency of not being able to stop or control worrying; this study considered the former question. Regarding depression, the HPS measured the frequency of having little interest or pleasure in doing things and the frequency of feeling down, depressed, or hopeless; this study considered the latter question. The Census Bureau used 90\% confidence intervals and 0.10 levels of significance to determine statistical validity. After data collection, the Census Bureau used various estimation procedures to adjust the household-level sampling base to account for external factors such as nonresponse, adults per household, and coverage.

Using the Census Bureau's data for weeks one (April 23 to May 5, 2020) and twelve (July 16 to July 21, 2020), we used the chi-square test of independence to analyze possible significance. This test was the most fitting because all the variables were categorical and there was a large sample size. For weeks one and twelve, this study tested if race, income bracket, age group, or sex were related to income loss, symptoms of anxiety, and symptoms of depression. Graphs were then created by calculating the conditional proportion of respondents in each category given that they were of a specific demographic group.

\section{Results}



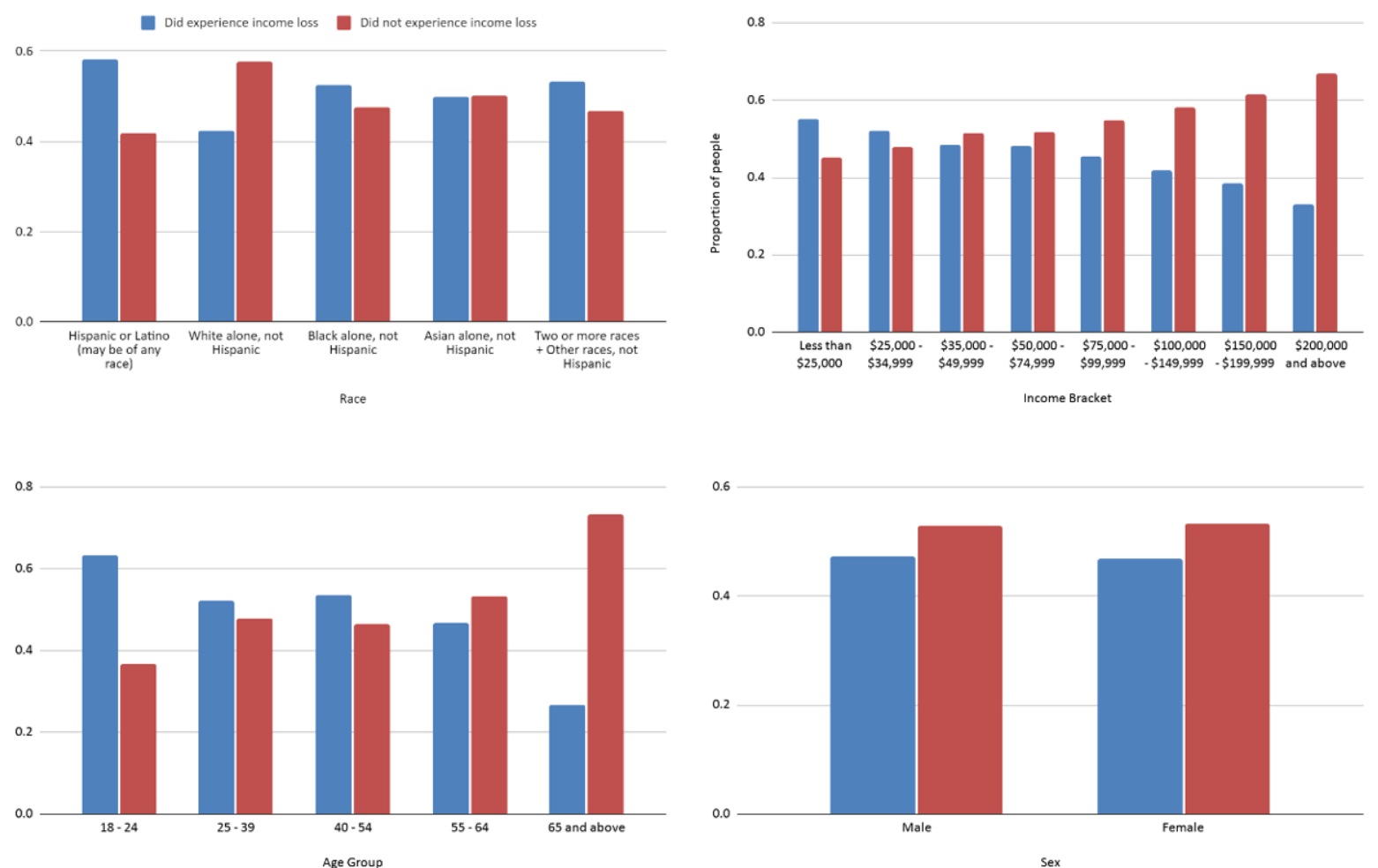

Figure 1. Experienced Loss of Employment Income by Race, Income Bracket, Age Group, and Sex, April 23 - May 5, 2020. $\mathrm{p}<0.05$.
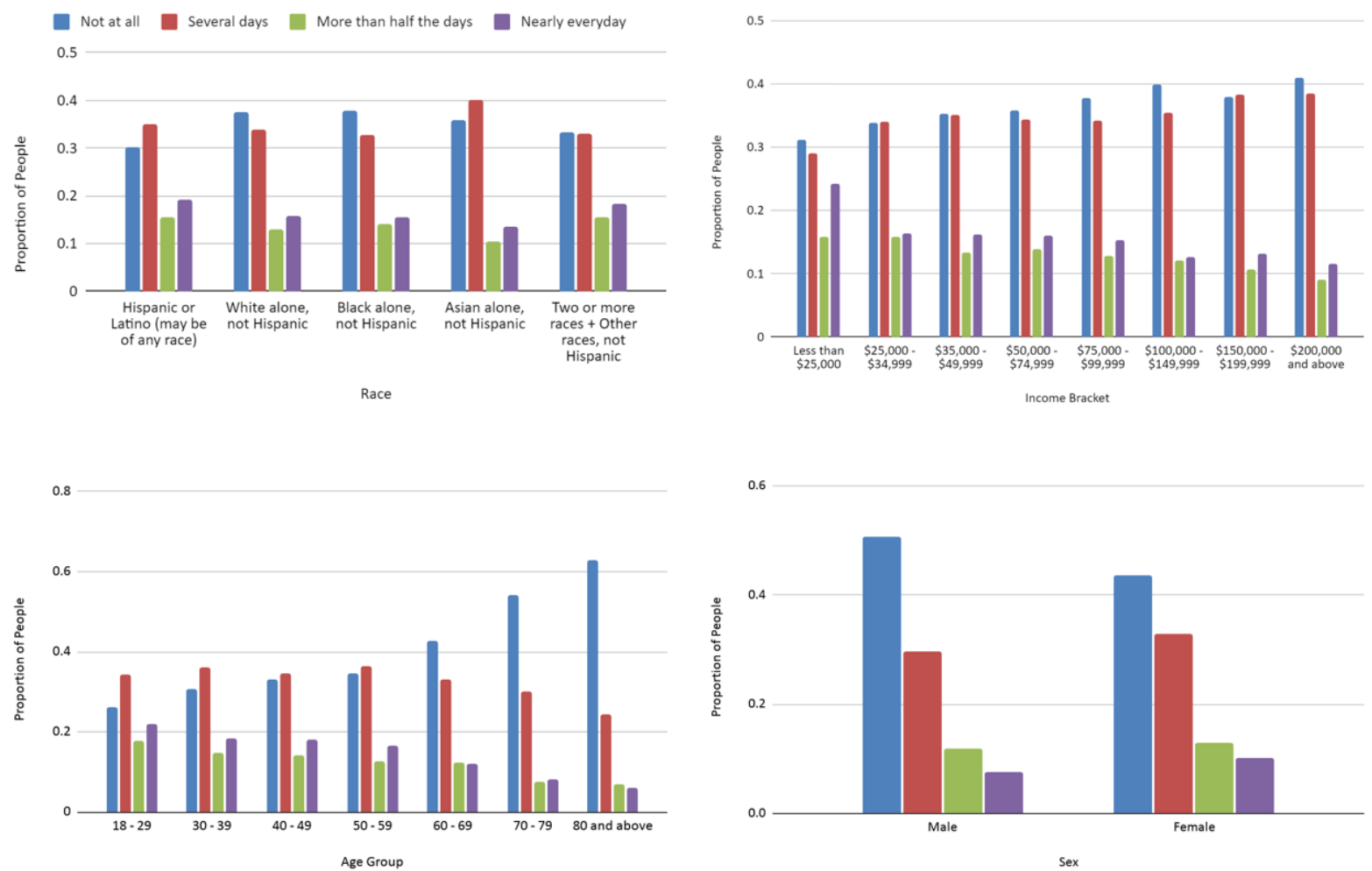

Figure 2. Experienced Frequency of Anxiety Symptoms by Race, Income Bracket, Age Group, and Sex, April 23 May 5, 2020. $\mathrm{p}<0.05$. 

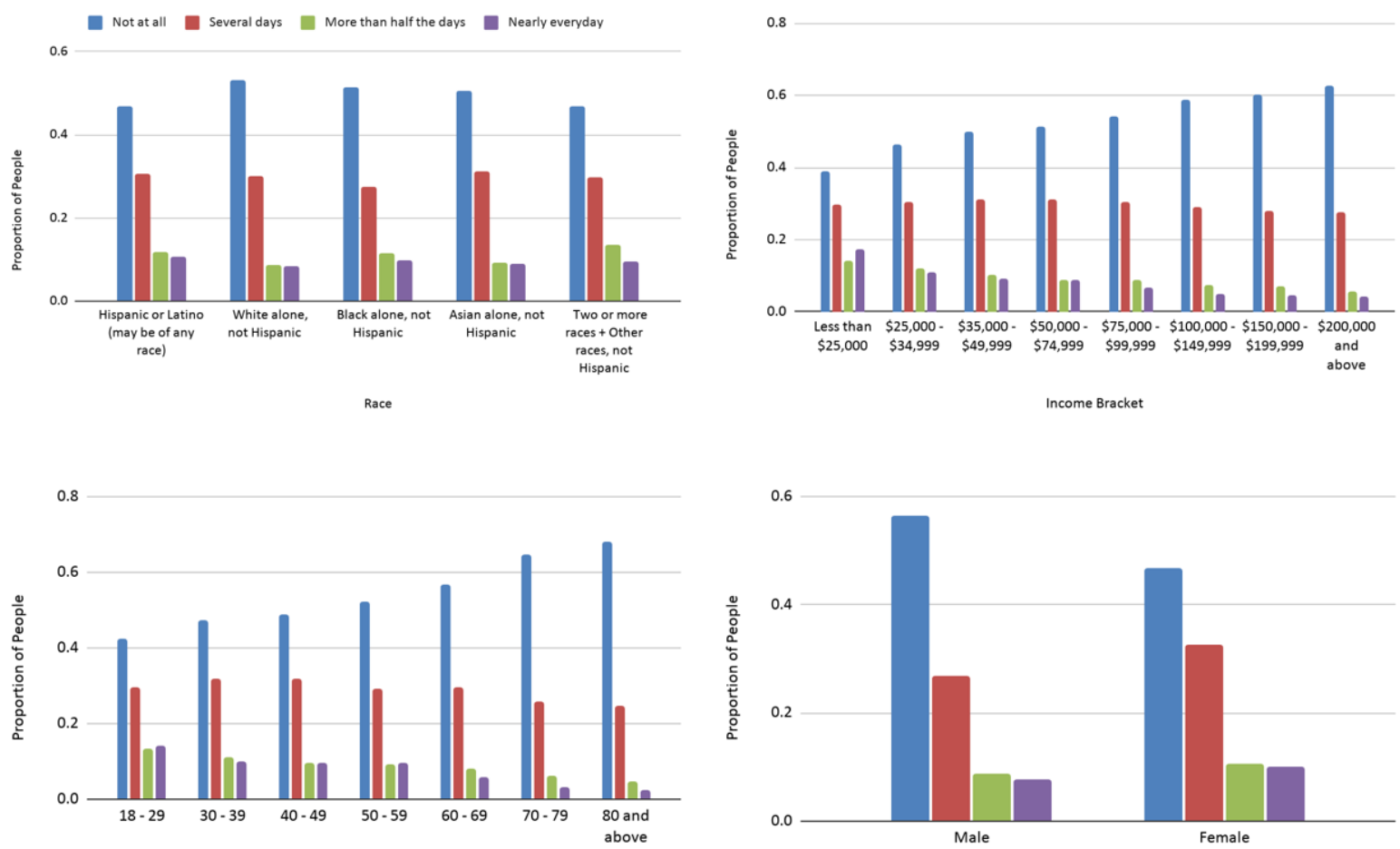

Age Group

Sex

Figure 3. Experienced Frequency of Depression Symptoms by Race, Income Bracket, Age Group, and Sex, April 23 - May 5, 2020. $\mathrm{p}<0.05$.
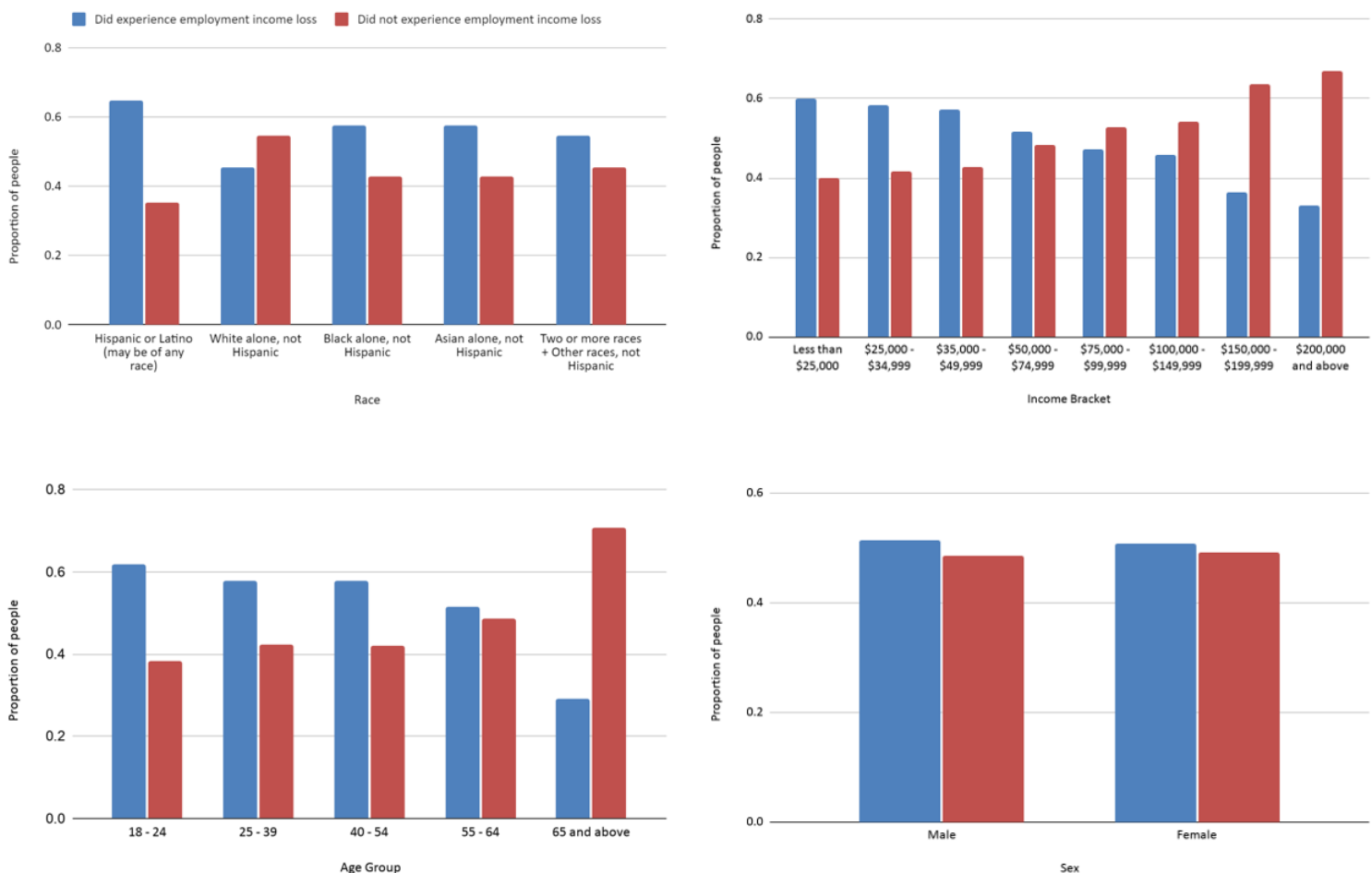

Figure 4. Experienced Loss of Employment Income by Race, Income Bracket, Age Group, and Sex, July 16 - July 21, 2020. $\mathrm{p}<0.05$. 

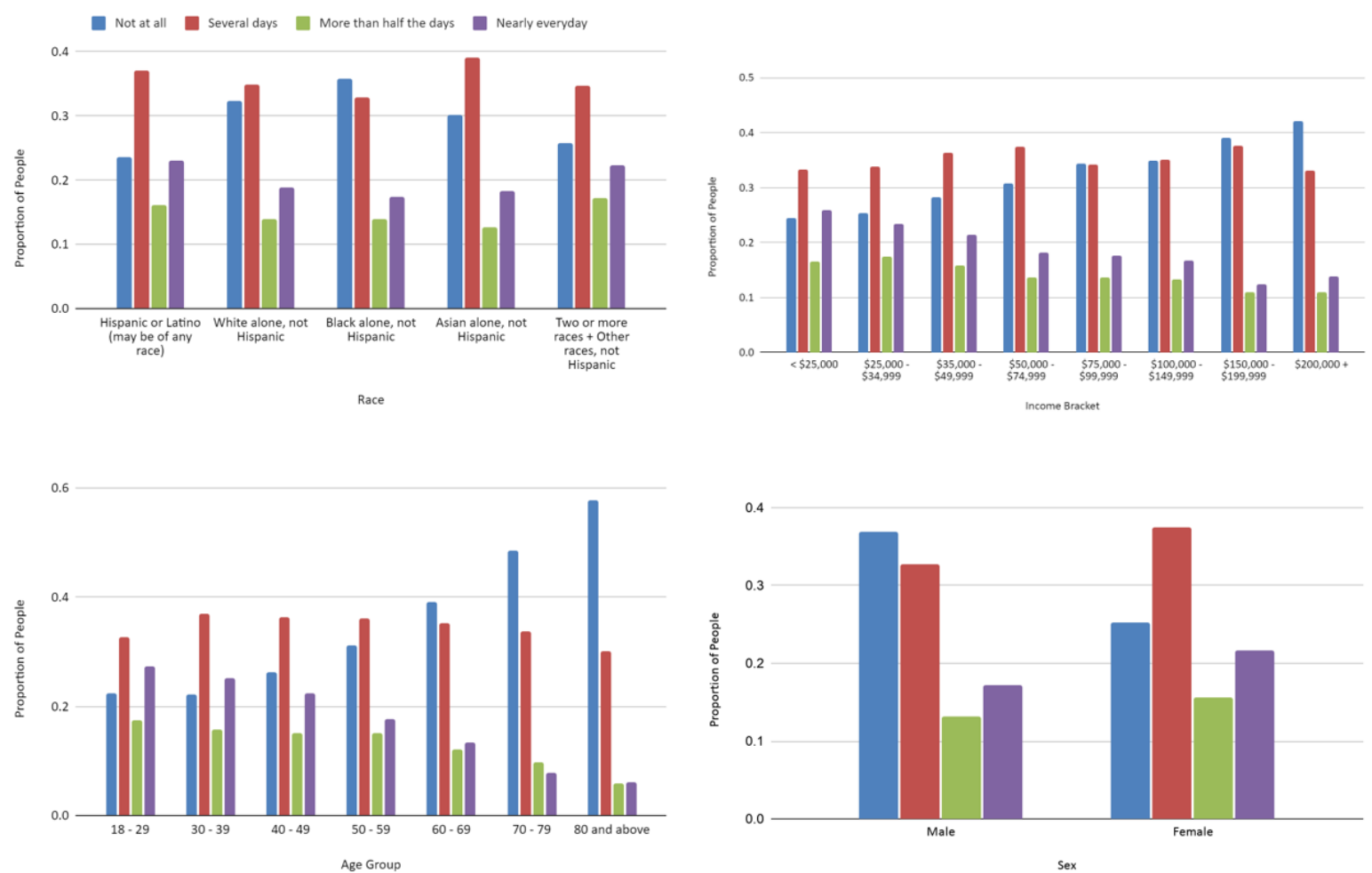

Figure 5. Experienced Frequency of Anxiety Symptoms by Race, Income Bracket, Age Group, and Sex, July 16 July 21, 2020. $\mathrm{p}<0.05$.
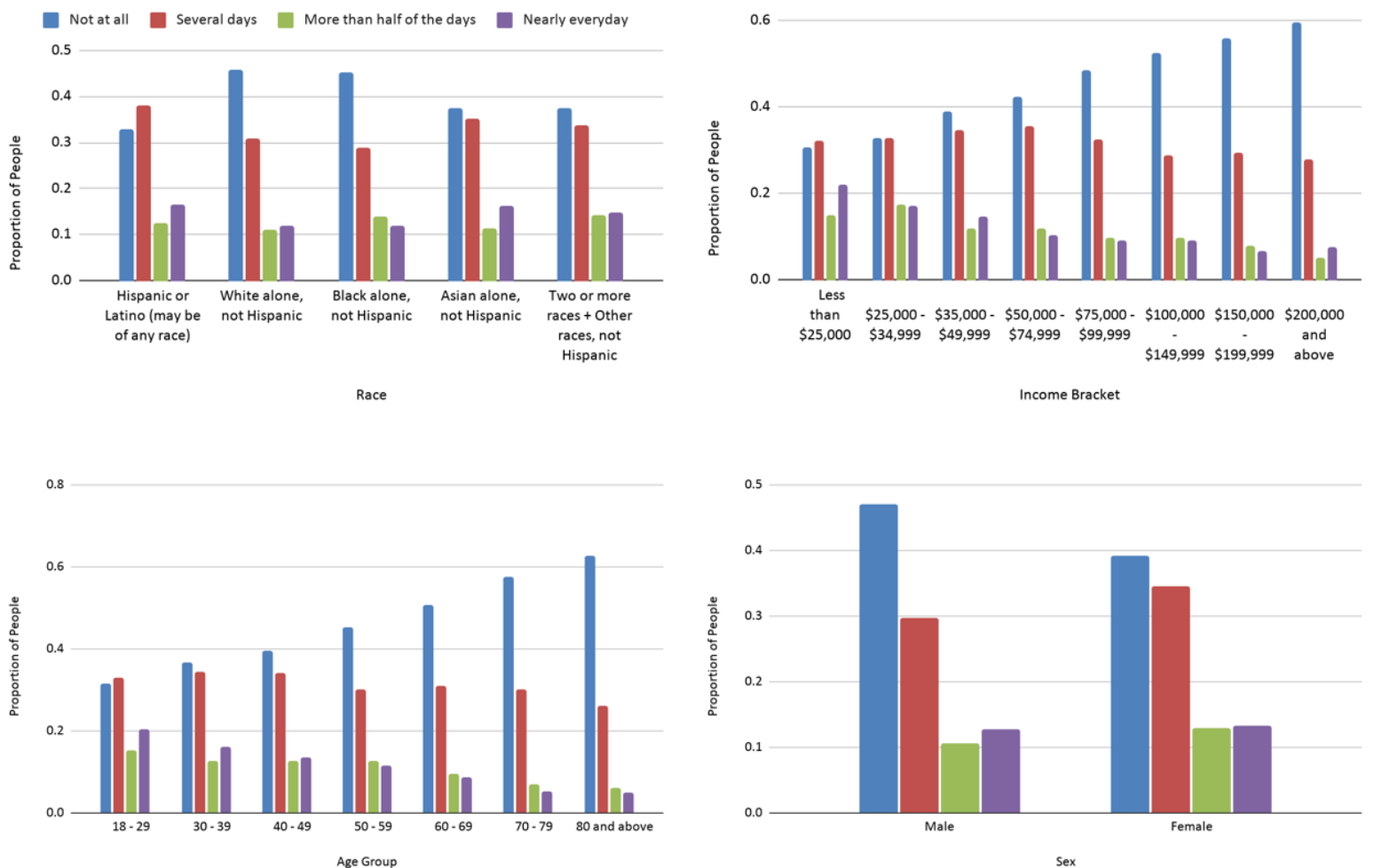

Figure 6. Experienced Frequency of Depression Symptoms by Race, Income Bracket, Age Group, and Sex, July 16 July 21, 2020. $\mathrm{p}<0.05$. 
All of the p-values obtained were less than the alpha value of 0.05 , indicating that they are all statistically significant. This means that the proportions within each demographic group were significantly different from each other at the $95 \%$ confidence level.

\section{Discussion}

\subsection{Employment income trends}

During the first data collection interval (April 23, 2020 to May 5, 2020), the proportion of Hispanics who experienced employment income loss was the greatest out of all races surveyed, with almost $60 \%$ reporting such income loss. The proportion of Whites who reported a decrease in employment income was the lowest at just over 40\%. Following Hispanics were Blacks, those who were of two or more races (50\%), and Asians (45\%). The response data also presents a clear trend between income bracket and loss of employment income. The proportion of people who experienced a loss in pay increased as income bracket decreased, and vice versa. Around 55\% of those who made less than $\$ 25,000$ experienced an income loss, whereas only about $30 \%$ of those who made more than $\$ 200,000$ experienced an income loss.

Similarly, among different age groups, a greater proportion of younger workers experienced a loss in income compared to their older counterparts. Over $60 \%$ of workers aged 18-24 reported a loss in income compared to those aged 65 and above, of which roughly only $25 \%$ experienced an income loss. Finally, in the first week of data collection, the proportions of males and females who did or did not experience an income loss were extremely close, with both sexes having almost $50 \%$ reporting an income loss.

For the twelfth week of data collection (July 16, 2020, to July 21, 2020), the proportion of Hispanics who reported a loss in income remained the greatest out of all races, increasing from $60 \%$ in the first week to around $65 \%$. The proportion of Whites who experienced income loss remained the lowest, though it also increased to roughly $45 \%$. Contrary to week one of data collection, data from week twelve showed that Blacks and Asians experienced extremely close proportions of those who experienced income loss at almost $60 \%$, and those of two or more races followed, with around 55\% experiencing an income loss. The relationship between income loss and the respective income bracket remained the same from week one to week twelve of data collection; $60 \%$ of those who made less than $\$ 25,000$ experienced an income loss, opposed to the $30 \%$ of those who made more than $\$ 200,000$ who experienced an income loss.

Again, a greater proportion of younger workers experienced an income loss compared to those who are older. As age increased, the proportion of workers who lost employment income decreased. Over $60 \%$ individuals aged 18 24 reported income loss, followed by ages 25-39 (x\%), 40-54 (x\%), 55-64 (x\%), and 65+ (x\%). . The drop was the greatest between those aged 55-64 and those 65 and above as it dropped from 50\% to 30\%. Between the sexes, males and females had very similar proportions again with around $50 \%$ experiencing an income loss in both sexes and just under 50\% not experiencing an income loss. Both sexes had a greater proportion of people who had an income loss compared to the first week.

\subsection{Anxiety trends}

For the first week of data collection, the proportions of Hispanics who experienced symptoms of anxiety several days, more than half the days, and nearly everyday of the week were higher than White, Black, and Asian counterparts. In addition, the proportions of people of two or more races experiencing various frequencies of anxiety symptoms were similar to those of Hispanics. The proportions of respondents who experienced anxiety symptoms were similar between White and Black respondents, although a greater proportion of Black respondents suffered from anxiety symptoms more than half the days than White respondents. Asian respondents experienced the lowest proportions of 
frequent anxiety symptoms out of all the races. When considering income level, there is a roughly inverse relationship between annual income and frequency of anxiety symptoms. Almost $70 \%$ of those who make less than $\$ 25,000$ annually reported experiencing anxiety symptoms at least several days per week.

As income increases, the proportions of those who experience anxiety symptoms several days, more than half the days, and nearly everyday decrease. There is also an inverse relationship between age and frequency of anxiety symptoms. Over $75 \%$ of the lowest age group, 18 to 29 years old, reported experiencing anxiety symptoms several days to nearly everyday of the week. By contrast, more than $60 \%$ of the highest age group, 80 years and above, reported not feeling symptoms of anxiety at all. When comparing the frequency of anxiety symptoms of the sexes, it is apparent that females experience a higher frequency. While over $50 \%$ of males experienced no symptoms of anxiety at all, only about $44 \%$ of females experienced no symptoms of anxiety at all.

When comparing the twelfth period of data collection to the first period, the proportion of those who experienced anxiety symptoms more than half the days or nearly everyday increased across all races. Likewise, the proportion of those who did not experience anxiety symptoms at all decreased across all races. A similar trend took place for income brackets; across those with annual incomes ranging from less than $\$ 25,000$ to between $\$ 150,000$ and $\$ 199,999$, the proportions of those experiencing anxiety symptoms more than half the days or nearly everyday increased, and the proportions of those not experiencing anxiety symptoms at all decreased. However, those who reported making $\$ 200,000$ and above experienced the opposite; the proportion of those who did not experience anxiety symptoms at all actually increased for that income bracket.

Across all age groups, the proportion of those who did not experience any anxiety symptoms at all decreased. However, the frequency of experiencing anxiety symptoms for both sexes increased. Despite this, females continued to experience higher rates of anxiety symptoms than their male counterparts.

\subsection{Depression trends}

In the first week of data collection, approximately $10.4 \%$ of Hispanic respondents experienced symptoms of depression nearly every day, followed by Blacks (9.7\%), multiracial individuals (9.5\%), Whites (8.3\%), and Asians (8.0\%). Additionally, there was a general inverse relationship between income and experienced symptoms of depression. People who made less than $\$ 25,000$ annually reported the highest frequency of depression, with $17.4 \%$ saying that they experienced symptoms every day. The relationship between respondents' age and frequency of depressive symptoms also exhibited a negative trend; as age increased, the percentage of individuals who experienced no symptoms of depression also increased, and the proportion of respondents who reported feeling down, depressed, or hopeless decreased. Almost 15\% of adults aged 18-24 reported experiencing depressive symptoms every day, the greatest percentage of any age group. A greater proportion of women (10.0\%) experienced symptoms of depression almost every day than men $(7.8 \%)$.

In the twelfth week of data collection, a greater proportion of people experienced any frequency (several days, more than half the days, or nearly everyday) of depressive symptoms across all races than reported in the first week. Hispanics remained the racial group with the highest percentage of respondents experiencing depression almost every day (16.5\%), followed by Asian people (16.1\%), multiracial people (14.7\%), White people (11.9), and Black people $(11.8 \%)$. The proportion of people that did not experience depression also decreased across all races. The proportion of White people who experienced the least frequent symptoms of depression, decreased from $53.2 \%$ in week one to $48.9 \%$ in week twelve.

Adults in all income brackets experienced a higher proportion of depressive symptoms several days, more than half the days, and nearly everyday, as well as a lower proportion of people experiencing no depressive symptoms. The proportion of those who experienced depressive symptoms also increased for all age groups. The percentage of adults aged 18-24 who experienced symptoms of depression almost every day increased from $14.3 \%$ to $20.3 \%$, and all other age groups sustained a similar increase. A greater proportion of both men (12.7\%) and women (13.3\%) experienced depressive symptoms nearly every day after the 12-week period as well. 


\subsection{Errors}

Possible errors in the HPS data consist of sampling error and nonsampling error. Types of nonsampling error include measurement error, coverage error, nonresponse error, imputation error. Sampling error means that the results drawn from the sample used in the HPS may not be the same as those of the entire population being sampled.

On the other hand, nonsampling error is the difference between the results of the sample and the true population. When incorrect information is provided by respondents due to factors such as unclear survey questions, it is defined as measurement error. Additionally, coverage error, or undercoverage, is when parts of the population are missed in the sample. Undercoverage occurs when housing units or individuals within a household are not accounted for by the survey. Coverage is disproportionately lower for males and African Americans, so to address this and the undercoverage of other demographic groups, the HPS weighted demographic groups differently while raking the data. Nonresponse error occurs when not all individuals included in the sample respond to the survey or provide information. The U.S. Census Bureau plans to analyze the nonresponse bias and determine its impact on the HPS. The surveys did have a relatively low response rate, with only a 3.8\% weighted response rate in the first week compared to the predicted 5\% response rate. Lastly, imputation error means that the values for missing data are estimated incorrectly. However, to mitigate the effects of these errors, the U.S. Census Bureau implemented quality control measures during all stages of the HPS: designing the survey itself, phrasing the survey's questions, and statistical analysis.

\section{Conclusion}

Previous studies suggest that COVID-19 caused economic struggles of greater severity to minority, lower-income, younger, and female demographic groups, while simultaneously causing the most prevalent increases in depression and anxiety rates for the same demographics. Our analysis from the U.S. Census Bureau data aligns with the findings of previously published research, as the graphed trends were similar to those outlined in the review of literature. In the future, researchers should examine the mental health of the groups most economically impacted by COVID-19 to uncover its long-term effects. Such research would examine whether those who were affected were able to financially or psychologically recover. Additionally, this literature review was focused on U.S. economic and mental impacts from COVID-19. To understand the global scale of COVID-19's impact, researchers should look for trends in mental health and economic impacts among demographic groups in other countries.

Future studies should investigate which factors of the pandemic affect the mental well-being of Americans the most; for example, loneliness caused by social distancing and quarantining, financial stress, and/or fear of contracting COVID-19 are some factors that could be studied. This research would be beneficial for understanding the root causes of worsening mental health during this pandemic and may help to effectively combat the increase in mental health disorders.

\section{Acknowledgements}

We are immensely grateful to Dr. Yuhsien Wu and Mr. Richard Wang for their insight and expertise that formulated our vision for our research. Their enthusiasm and attention to detail inspired us to write this paper for the community. Samantha White, graduate of Harvard College, has also dedicated her invaluable time and assistance in providing comments on topics discussed in this paper. Furthermore, we would like to thank Mr. Li for his guidance in aiding us with our statistical analysis of the data we assembled. Finally, it is with great pleasure that we thank the whole entirety of BranchOut! Veritas Education Leaders—its student members, families, and supporters_-for being the biggest motivators for our team. 


\section{References}

Albert, P. R. (2015, July). Why is depression more prevalent in women? Retrieved August, 2020, from https://www.ncbi.nlm.nih.gov/pmc/articles/PMC4478054/

Amadeo, K. (2020c, June 30). The 9 principal effects of the great depression. The Balance. Retrieved July 28, 2020, from https://www.thebalance.com/effects-of-the-great-depression-4049299

American Psychiatric Association. (2017). Mental health disparities: diverse populations. American Psychiatric Association. Retrieved July 28, 2020, from https:/www.psychiatry.org/psychiatrists/culturalcompetency/education/mental-health-facts

Anxiety and Depression Association of America (2020). Low-Income Communities. Retrieved February 6, 2021 , from https://adaa.org/finding-help/low-income-communities

Asnaani, A., Richey, A., Dimaite, R., Hinton, D., \& Hofmann, S. (2010). Across-ethnic comparison of lifetime prevalence rates of anxiety disorders. The Journal of Nervous and Mental Disease, 198(8), 551-555. https://doi.org/10.1097/NMD.0b013e3181ea169f

Banerjee, D. (2020). 'Age and ageism in COVID-19': Elderly mental health-care vulnerabilities and needs. Asian Journal of Psychiatry, 51, 102154. https://doi.org/10.1016/j.ajp.2020.102154

Bartuska, A., Shtasel, D., \& Marques, L. (2020). Understanding the cracks: What COVID-19 means for the mental health of the marginalized in the United States and opportunities for response. Anxiety and Depression Association of America. Retrieved July 31, 2020, from https://adaa.org/learnfrom-us/from-the-experts/blog-posts/professional/understanding-cracks-what-covid-19-means

Bekaert, G., Engstrom, E., \& Ermolov, A. (n.d.). Aggregate demand and aggregate supply effects of covid-19: A real-time analysis. Finance and Economics Discussion Series Divisions of Research \& Statistics and Monetary Affairs Federal Reserve Board, Washington, D.C. Retrieved July 28, 2020, from https://doi.org/10.17016/FEDS.2020.049

Bertrand, M. (2020, May 5). Coronavirus pandemic has harmed lower-income workers the most. Uchicago News. Retrieved July 28, 2020, from https://news.uchicago.edu/story/coronavirus-pandemic-has-harmed-lowerincome-workers-most

Breslau, J., Aguilar-Gaxiola, S., Kendler, K., Su, M., Williams, D., \& Kessler, R. (2006). Specifying race-ethnic differences in risk for psychiatric disorder in a USA national sample. Psychological Medicine, 36(1), 57-68. https://doi.org/10.1017/S0033291705006161 = Centers for Disease Control and Prevention. (2020, July 22). Mental health. CDC. Retrieved July 29, 2020, from https://www.cdc.gov/nchs/covid19/pulse/mental-health.htm

Chakravarty, M., \& Philipose, M. (2009, August 10). Economic impact of swine flu. Livemint. Retrieved July 28, 2020, from https://www.livemint.com/Money/ALhNfoq6XIf5Vxja4fmniM/Economic-impact-of-swine-flu.html

Chiavegatto Filho, A. D. P., Kawachi, I., Wang, Y. P., Viana, M. C., \& Andrade, L. H. S. G. (2013). Does income inequality get under the skin? A multilevel analysis of depression, anxiety and mental disorders in São Paulo, Brazil. Journal of Epidemiology and Community Health, 67(11), 966-972. https://doi.org/10.1136/jech-2013-202626

Cubanski, J., Neuman, T., \& Koma, W. (2020, May 13). Older adults are hit hard by COVID-19-and also losing jobs. Kaiser Family Foundation. Retrieved July 28, 2020, from https:/www.kff.org/coronavirus-policy-watch/older-adults-are-hit-hard-by-covid-19-and-also-losing-jobs/\# : : text=The\%20unemployment\%20rate\%20among\%20people,people\%20ages\%2055\%20to\%2064.

Department of Gender and Women's Health. (2002, June). Gender and mental health. WHO. Retrieved August 3 , 2020, from https:/www.who.int/gender/other_health/genderMH.pdf

Despard, M., Grinstein-Weiss, M., Chun, Y., \& Roll, S. (2020, July 13). COVID-19 job and income loss leading to more hunger and financial hardship. Brookings. Retrieved July 28, 2020, from 
https:/www.brookings.edu/blog/up-front/2020/07/13/covid-19-job-and-income-loss-leading-to-morehunger-and-financial-hardship/

Dijkstra-Kersten, S. M. A., Biesheuvel-Leliefeld, K. E. M., Van Der Wouden, J. C., Penninx, B. W. J. H., \& Van Marwijk, H. W. J. (2015). Associations of financial strain and income with depressive and anxiety disorders. Journal of Epidemiology and Community Health, 69(7), 660-665. https://doi.org/10.1136/jech2014-205088

Duca, J. V. (2013, November 22). Subprime mortgage crisis. Federal Reserve History. Retrieved July 28, 2020, from https://www.federalreservehistory.org/essays/subprime_mortgage_crisis?WT.si_n=Search\&WT.si_x=3\#ho $\mathrm{w}$

Dunlop, D. D., Song, J., Lyons, J. S., Manheim, L. M., \& Chang, R. W. (2003). Racial/Ethnic differences in rates of depression among preretirement adults. American Journal of Public Health, 93(11), 1945-1952. https://doi.org/10.2105/ajph.93.11.1945

Forbes, M. K., \& Krueger, R. F. (2019). The great recession and mental health in the United States. Clinical Psychological Science, 7(5), 900-913. https://doi.org/10.1177/2167702619859337

Graham, C., Grinstein-Weiss, M., \& Roll, S. (2020, June 24). Well-being and mental health amid COVID-19: differences in resilience across minorities and whites. Brookings. Retrieved July 31, 2020, from https://www.brookings.edu/research/well-being-and-mental-health-amid-covid-19-differences-inresilience-across-minorities-and-whites/

Gramigna, J., Lee, J., Lipson, S. K., Parikh, S. V., \& Hawkley, L. C. (2020, April 8). COVID-19's mental health effects by age group: Children, college students, working-age adults and older adults. Helio. Retrieved July 28, 2020, from https://www.healio.com/news/psychiatry/20200408/covid19s-mental-health-effects-byage-group-children-college-students-workingage-adults-and-older-ad

Hamel, L., \& Salganicoff, A. (2020, April 6). Is there a widening gender gap in coronavirus stress? Kaiser Family Foundation. Retrieved August 5, 2020, from https:/www.kff.org/policy-watch/isthere-widening-gender-gap-in-coronavirus-stress/

Henry-Nickie, M., \& Hudak, J. (2020, May 19). Social distancing in Black and white neighborhoods in Detroit: A data-driven look at vulnerable communities. Brookings. https://www.brookings.edu/blog/fixgov/2020/05/ 19/social-distancing-in-black-and-white-neighborhoods-in-detroit-a-data-driven-look-at-vulnerablecommunities/

Himle, J. A., Baser, R. E., Taylor, R. J., Campbell, R. D., \& Jackson, J. S. (2009). Anxiety disorders among African Americans, blacks of Caribbean descent, and non-Hispanic whites in the United States. Journal of Anxiety Disorders, 23(5), 578-590. https://doi.org/10.1016/j.janxdis.2009.01.002

Hoynes, H., Miller, D. L., \& Schaller, J. (2012). Who suffers during recessions? Journal of Economic Perspectives, 26(3), 27-48. https://doi.org/10.1257/jep.26.3.27

Jalloh, M. F., Li, W., Bunnell, R. E., Ethier, K. A., O'Leary, A., Hageman, K. M., Sengeh, P., Jalloh, M. B., Morgan, O., Hersey, S., Marston, B. J., Dafae, F., \& Redd, J. T. (2018). Impact of Ebola experiences and risk perceptions on mental health in Sierra Leone, July 2015. BMJ Global Health, 3(2), e000471. https://doi.org/10.1136/bmjgh-2017-000471

Kalev, A. (2020, April 20). Research: U.S. unemployment rising faster for women and people of color. Harvard Business Review. Retrieved August 5, 2020, from https://hbr.org/2020/04/research-u-s-unemployment-rising-faster-for-women-and-people-of-color

Kirzinger, A., Kearney, A., Hamel, L., \& Brodie, M. (2020, April 2). KFF Health Tracking Poll - early April 2020 : The impact of coronavirus on life in America. Kaiser Family Foundation. Retrieved July 31, 2020, from https://www.kff.org/health-reform/report/kff-health-tracking-poll-early-april-2020/

Kochhar, R. (2020a, June 9). Hispanic women, immigrants, young adults, those with less education hit hardest by COVID-19 job losses. Pew Research Center. Retrieved July 28, 2020, from https://pewrsr.ch/2MW8M17 
Kochhar, R. (2020b, June 11). Unemployment rose higher in three months of COVID-19 than it did in two years of the Great Recession. Pew Research Center. Retrieved July 28, 2020, from https://pewrsr.ch/2UADTTZ

Lenzen, M., Li, M., Malik, A., Pomponi, F., Sun, Y.-Y., Wiedmann, T., Faturay, F., Fry, J., Arne Geschke, B. G., Gómez-Paredes, J., Kanemoto, K., Kenway, S., Nansai, K., Prokopenko, M., Wakiyama, T., Wang, Y., \& Yousefzadeh, M. (2020). Global socio-economic losses and environmental gains from the Coronavirus pandemic. Plos One, 15(7). https://doi.org/10.1371/Journal.pone.0235654

Levine, C. (2020, June 23). Single moms hit hard by economic impact of COVID-19. Nonprofit Quarterly. Retrieved August 5, 2020, from https://nonprofitquarterly.org/single-moms-hit-hard-by-economic-impact-of-covid$19 /$

Library of Congress. (n.d. -a). Americans react to the Great Depression. Library of Congress. Retrieved July 29 , 2020, from

https://www.loc.gov/teachers/classroommaterials/presentationsandactivities/presentations/timeline/depwwii /depress/

Library of Congress. (n.d. -b). Race relations in the 1930s and 1940s. Library of Congress. Retrieved July 29, 2020, from

http://www.loc.gov/teachers/classroommaterials/presentationsandactivities/presentations/timeline/depwwii/ race/

Lock, H. (2020, May 21). Women are bearing the brunt of COVID-19 lockdown anxiety in the UK. Global Citizen. Retrieved August 3, 2020, from https://www.globalcitizen.org/en/content/women-uk-covid-19-anxiety-mental-health/

Mak, I., Chu, C., Pan, P., Yiu, M., \& Chan, V. (2009). Long-term psychiatric morbidities among SARS survivors. Science Direct, 31(4), 318-326. https://doi.org/10.1016/j.genhosppsych.2009.03.001

Mather, M. (2015, November 4). Effects of the Great Recession on older Americans' health and well-being. Today's Research on Aging. Retrieved July 28, 2020, from https://www.prb.org/todays-research-aging-greatrecession-2/

McHenry, J., Carrier, N., Hull, E., \& Kabbaj, M. (2014, January). Sex differences in anxiety and depression: Role of testosterone. Retrieved August, 2020, from https://www.ncbi.nlm.nih.gov/pmc/articles/PMC3946856/

Mckibbin, W. \& Sidorenko, A.A. (2006). "Global Macroeconomic Consequences of Pandemic Influenza”, Lowy Institute for International Policy, Sydney.

McLean, C. P., Asnaani, A., Litz, B. T., \& Hofmann, S. G. (2011, August). Gender differences in anxiety disorders: Prevalence, course of illness, comorbidity and burden of illness. Retrieved August 5, 2020, from https://www.ncbi.nlm.nih.gov/pmc/articles/PMC3135672/

Miller, R. S., \& Labonte, M. (2020). COVID-19: U.S. economic effects. Congressional Research Service. https://crsreports.congress.gov/product/pdf/IN/IN11388.

Miyamoto, I. (2020, May). COVID-19 healthcare workers: 70\% are women. Security Nexus Perspectives. Retrieved August 4, 2020, from https://apcss.org/wp-content/uploads/2020/05/Security-nexus-COVID-19-HealthcareWorkers-miyamoto.pdf

Mossakowski, K. (2014). Social causation and social selection. Wiley Online Library. Retrieved July 28, 2020, from https://doi.org/10.1002/9781118410868.wbehibs262

National Alliance on Mental Illness. (2019, September). Mental health by the numbers. National Alliance on Mental Illness. Retrieved July 28, 2020, from https://www.nami.org/mhstats

Nicola, M., Alsafi, Z., Sohrabi, C., Kerwan, A., Al-Jabir, A., Iosifidis, C., Agha, M., \& Agha, R. (2020). The socio-economic implications of the coronavirus pandemic (COVID-19): A review. International Journal of Surgery, 78, 185-193. https://doi.org/10.1016/j.ijsu.2020.04.018.

Noppert, G. (2020, April 14). COVID-19 is hitting Black and poor communities the hardest. JSTOR Daily. Retrieved July 28, 2020, from https:/daily.jstor.org/covid-10-hitting-black-poor-communities-hardest/

Parker, K., Menasce Horowitz, J., \& Brown, A. (2020, April 21). About half of lower-income Americans report 
household job or wage loss due to COVID-19. Pew Research Center. Retrieved July 28, 2020, from https://www.pewsocialtrends.org/2020/04/21/about-half-of-lower-income-americans-report-household-jobor-wage-loss-due-to-covid-19/

Pew Research Center (2020, March 30). Most Americans say coronavirus outbreak has impacted their lives.

Retrieved July 28, 2020, from

https://www.pewsocialtrends.org/2020/03/30/most-americans-say-coronavirus-outbreak-has-impacted-their -lives/

Purtle, J. (2020). COVID-19 and mental health equity in the United States. Social Psychiatry and Psychiatric Epidemiology, 1-3. https://doi.org/10.1007/s00127-020-01896-8

Qiu, W., Chu, C., Mao, A., \& Wu, J. (2018, June 28). The impacts on health, society, and economy of SARS and H7N9 outbreaks in china: a case comparison study. Hindawi. Retrieved July 28, 2020, from https://doi.org/10.1155/2018/2710185

Recovery Across Mental Health. (n.d.). Gender differences in mental health. Recovery Across Mental Health. Retrieved August 3, 2020, from https://ramh.org/guide/gender-differences-in-mental-health/

Rich, R. (2013, November 22). The Great Recession. Federal Reserve History. Retrieved July 28, 2020, from https://www.federalreservehistory.org/essays/great_recession_of_200709

Romer, C. (n.d.). Great Depression. Encyclopedia Britannica. Retrieved July 28, 2020, from https://www.britannica.com/event/Great-Depression/Portrayals-of-hope

Schaeffer, K., \& Rainie, L. (2020, June 16). Experiences with the COVID-19 outbreak can vary for Americans of different ages. Pew Research. Retrieved July 28, 2020, from https://www.pewresearch.org/fact-tank/2020/06/16/experiences-with-the-covid-19-outbreak-can-vary-for-a mericans-of-different-ages/

Schanzenbach, D. W., Nunn, R., Bauer, L., Boddy, D., \& Nantz, G. (2016, May 23). Nine facts about the Great Recession and tools for fighting the next downturn. The Hamilton Project, 1-24. Retrieved July 28, 2020, from https://www.brookings.edu/research/nine-facts-about-the-great-recession-and-tools-for-fighting-thenext-downturn/

Substance Abuse and Mental Health Services Administration. (n.d.). Double jeopardy: COVID-19 and behavioral health disparities for Black and Latino communities in the U.S. (Submitted by OBHE). Retrieved July 28, 2020, from https://www.samhsa.gov/sites/default/files/covid19-behavioral-health-disparities-black-latino-communities. pdf

Swagel, P. (2010, April 28). The cost of the financial crisis: The impact of the September 2008 economic collapse (Cost of the financial crisis; Report No. 18). PEW. Retrieved July 28, 2020, from https://www.pewtrusts.org/en/research-and-analysis/reports/2010/04/28/the-impact-of-the-september-2008economic-

collapse\#: :text=That $\% 20$ equates $\% 20$ to $\% 20$ an $\% 20$ average,income $\% 20$ for $\% 20$ each $\% 20$ U.S. $\% 20$ househol d.\&text=Jobs $\% 20 \%$ E2\%80\%93\%205.5\%20million\%20more\%20American,the $\% 20$ September $\% 202008 \% 2$ $0 \mathrm{CBO} \% 20$ forecast.

The National Institute of Mental Health. (2017, November). Generalized anxiety disorder. The National Institute of Mental Health. Retrieved July 28, 2020, from https:/www.nimh.nih.gov/health/statistics/generalized-anxiety-disorder.shtml

The National Institute of Mental Health. (2019a, February). Major depression. The National Institute of Mental Health. Retrieved July 28, 2020, from https://www.nimh.nih.gov/health/statistics/major-depression.shtml

The National Institute of Mental Health. (2019b, February). Mental illness. The National Institute of Mental Health. Retrieved July 29, 2020, from https://www.nimh.nih.gov/health/statistics/mental-illness.shtml

United Nations. (2020, April 9). Policy brief: The impact of COVID-19 on women. Retrieved August 5, 2020, from https://www.unwomen.org/en/digital-library/publications/2020/04/policy-brief-the-impact-of-covid-19-on- 
women

U.S. Bureau of Labor Statistics, The employment situation - June 2020, Doc. (2020, July 2). https://www.bls.gov/news.release/empsit.nr0.htm

United States Census Bureau. (2020a, June). Household Pulse Survey Public Use File (PUF). United States Census Bureau. Retrieved January 31, 2021, from https://www.census.gov/programs-surveys/household-pulse-survey/datasets.html

United States Census Bureau. (2020b, May). Week 1 household pulse survey: April 23 - May 5. United States Census Bureau. Retrieved July 31, 2020, from https://www.census.gov/data/tables/2020/demo/hhp/hhp1.html

United States Census Bureau. (2020c, July 22). Week 11 Household Pulse Survey: July 9 - July 14. United States Census Bureau. Retrieved July 31, 2020, from https://www.census.gov/data/tables/2020/demo/hhp/hhp11.html

Wan, W. (2020, May 4). The coronavirus pandemic is pushing America into a mental health crisis. Washington Post. Retrieved July 28, 2020, from https:/www.washingtonpost.com/health/2020/05/04/mental-healthcoronavirus/

Wardrip, K., \& Tranfaglia, A. (2020, April). Which workers will be most impacted? Federal Reserve Bank of Philadelphia. Retrieved July 28, 2020, from https:/www.philadelphiafed.org/covid-19/covid-19-equity-inrecovery/which-workers-will-be-most-impacted

Williams, D.R., González, H. M., Neighbors, H., Nesse, R., Abelson, J. M., Sweetman, J., \& Jackson, J. J. (2007). Prevalence and distribution of major depressive disorder in African Americans, Caribbean Blacks, and Non-Hispanic Whites: Results from the national survey of American life. Archives of General Psychiatry, 64(3), 305-315. https://doi.org/10.1001/archpsyc.64.3.305

Wilson, C. (2020, April 15). These graphs show how COVID-19 is ravaging New York City's low-income neighborhoods. TIME. Retrieved July 28, 2020, from https:/www.yahoo.com/lifestyle/york-city-exposesstark-disparity-165428765.html 